\title{
Editorial: Food Analytical Methods in Latin America-FANM-LATAM
}

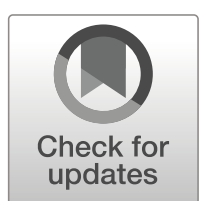

\author{
Fabíola Manhas Verbi Pereira ${ }^{1}$ Edenir Rodrigues Pereira-Filho ${ }^{2}$
}

Received: 30 August 2019 / Accepted: 9 September 2019/Published online: 22 November 2019

(C) Springer Science+Business Media, LLC, part of Springer Nature 2019

Food quality control is an important field in food science. Since 2008, the Food Analytical Methods journal is dedicated to the presentation of new analytical methods for food analysis, focusing on the determination of organic and inorganic contaminants, and nutrients. In this special issue, we tried to organize studies dedicated to analytical methods presented by authors from Latin America. A total of 33 manuscripts were accepted for publication and several aspects were evaluated as described in Table 1.
The mentioned studies presented many applications dedicated to several analytical matrices of food samples. In all cases, regional types of food/sample were evaluated demonstrating its importance for Latin America. We have to highlight the use of chemometric techniques. In addition, the challenge task of the presented methods is to reach simplicity and useful information focusing in high sensitivity. Figure 1 shows a pictorial description of the contributions, and we hope that this special issue increased the knowledge of this relevant scientific field.
Edenir Rodrigues Pereira-Filho

erpf@ufscar.br

1 Grupo de Abordagens Analítica Alternativas (GAAA), Instituto de Química, Universidade Estadual Paulista (Unesp), Araraquara, SP 14800-060, Brazil

2 Grupo de Análise Instrumental Aplicada (GAIA), Departamento de Química, Universidade Federal de São Carlos (UFSCar), São Carlos, SP 13565-905, Brazil 
Fig. 1 Main characteristics of the proposed food analytical methods published in this special issue

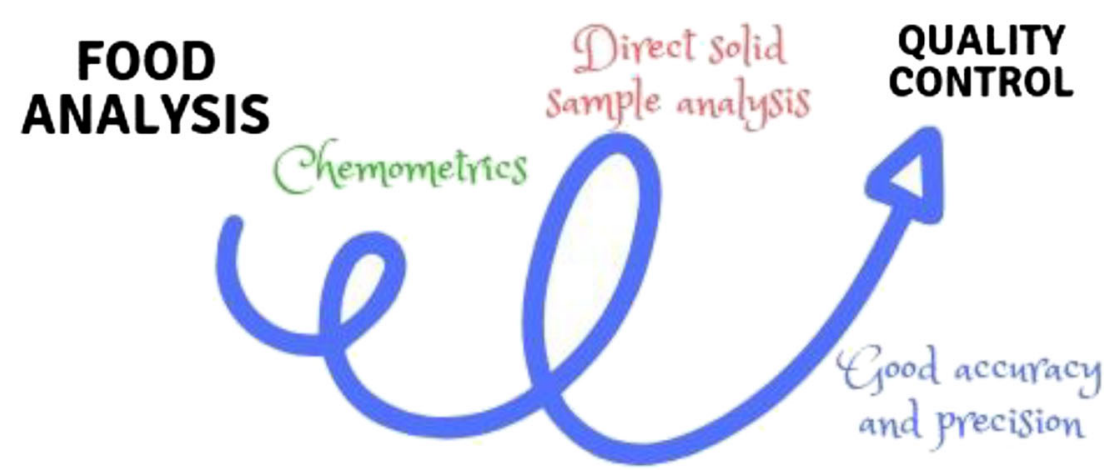

Table 1 Main topics observed in the accepted manuscripts for Food Analytical Methods in Latin America-FANM-LATAM

Topic evaluated

Adulterants in roasted and ground coffee by NIR hyperspectral imaging

Aromas in gummy candies

Bioaccessibility and ICP OES

Bioactive compounds and antioxidant capacity in freeze-dried red cabbage

Brazilian cachaça analysis

Chemometrics and FTIR for quality of specialty coffees

Coffee quality control using microNIR and spectroanalytical techniques

Data fusion for assessment of olive oil

Determination of florfenicol and florfenicol amine in tilapia by LC-MS/MS

Direct analysis in chocolate by EDXRF

Dispersive solid phase extraction (d-SPE) as a clean-up step for phenolic compounds determination

Electroanalytical determination of thiram and carbendazim in samples of fresh fruit juices

Fish oil analysis

Fractionation for in natura and aged beef
Topic evaluated

Grape nectars adulteration

Halogens and sulfur determination

Image analysis for ethanol and color determination in drink samples

Lead migration in clay pots

Lipoxygenase Activity in Common Beans by UV and NMR spectroscopy Milk analysis and classification

Mineral determination in peppers

Phenolic compounds studies

Powdered refreshments analysis

Sample preparation for nutrient evaluation in cassava flour

Sugarcane analysis

Thermometric titration

Trace elements in meat and fish samples by MIP OES

Yerba mate classification

\section{Compliance with ethical standards}

Conflict of interest Fabíola Manhas Verbi Pereira declares that she has no conflict of interest. Edenir Rodrigues Pereira-Filho declares that he has no conflict of interest.
Publisher's Note Springer Nature remains neutral with regard to jurisdictional claims in published maps and institutional affiliations. 